Français, anglais et allemand: trois langues rivales entre 1850 et 1945. French, English and German: three languages in competition between 1850 and 1945

\title{
La société espagnole à l'écoute des grandes langues européennes : le français et l'allemand en Espagne entre 1880 et 1930
}

\section{Alicia Piquer Desvaux}

\section{(2) OpenEdition Journals}

\section{Édition électronique}

URL : https://journals.openedition.org/dhfles/4083

DOI : $10.4000 /$ dhfles.4083

ISSN : 2221-4038

\section{Éditeur}

Société Internationale pour l'Histoire du Français Langue Étrangère ou Seconde

\section{Édition imprimée}

Date de publication : 1 décembre 2014

Pagination : 109-124

ISSN : 0992-7654

\section{Référence électronique}

Alicia Piquer Desvaux, « La société espagnole à l'écoute des grandes langues européennes : le français et l'allemand en Espagne entre 1880 et 1930 », Documents pour l'histoire du français langue étrangère ou seconde [En ligne], 53 | 2014, mis en ligne le 10 septembre 2017, consulté le 28 mai 2021. URL : http://journals.openedition.org/dhfles/4083 ; DOI : https://doi.org/10.4000/dhfles.4083

Ce document a été généré automatiquement le 28 mai 2021 


\title{
La société espagnole à l'écoute des grandes langues européennes : le français et l'allemand en Espagne entre 1880 et 1930
}

\author{
Alicia Piquer Desvaux
}

\section{Introduction}

1 La nouvelle situation politique européenne à partir de 1870, provoquée par la défaite française devant l'Allemagne de Bismarck et la chute du Second Empire, puis le prestige de plus en plus grandissant de l'empire britannique au temps de la reine Victoria, fait que le lustre international de la France commence à se ternir. La proclamation de la Troisième République va coïncider d'ailleurs avec la restauration de la monarchie en Espagne et cela contribuera à éloigner celle-ci de son voisin du nord pour l'approcher des autres deux grandes puissances européennes avec lesquelles elle avait des affinités politiques renouvelées. Nous allons nous appliquer, au long de cette étude, à étudier le cas concernant les nouvelles relations culturelles hispano-allemandes entre 1880 et 1930 (date qui marque la fin de la dictature de Primo de Rivera, ce qui coïncide avec la montée de l'agitation républicaine), le tout axé sur la situation des langues étrangères et spécialement sur leur enseignement, jetant en même temps un regard tout particulier sur la langue allemande dans ce concert des langues. Car il est indéniable que pendant ces cinquante ans on s'intéressera en Espagne à la culture allemande, puis à la langue qui la véhicule, même si le français continue à s'imposer partout comme première langue étrangère. En tout cas à partir des années 1830 à 1850, à l'occasion des différents plans d'études qui s'en suivent alors, surtout ceux de 1836 et 1845, puis celui qui résulte de la promulgation de la loi d'Instruction publique de 1857 (connue sous le nom de loi Moyano), les langues étrangères commencent à trouver leur place dans le système éducatif espagnol. Mais s'il est vrai qu'on connaît bien la place et le rôle du français, langue étrangère hégémonique alors en Espagne, on connaît beaucoup moins 
la vraie situation d'autres langues étrangères comme c'est le cas de l'anglais et de l'allemand, ce que nous allons nous efforcer de préciser ici.

\section{Les premiers pas de la langue et la culture allemandes en Espagne avant 1880}

2 La décennie 1880 représente un point d'inflexion pour ce qui concerne la présence de la langue et de la culture allemandes en Espagne, comme résultat de la nouvelle situation politique qui s'en suivit après la restauration monarchique de 1875 . Il nous faut néanmoins jeter un regard rapide en arrière. Car s'il est incontestable que la situation du français reste hégémonique dans tous les plans d'études qui se succèdent au long du XIX ${ }^{e}$ siècle, il n'est pas moins vrai qu'à partir des années 1830 comme conséquence des nouveaux contacts qui commencent à s'établir alors, pour des raisons diverses ${ }^{1}$, entre l'Espagne et des pays européens autres que la France, la situation commence à changer. Pour le cas des relations hispano-allemandes l'attrait et l'influence que la philosophie krausiste va exercer sur certaines élites intellectuelles espagnoles aura des conséquences importantes. De là cette relation plus ou moins constante qui commence à s'établir de la part de cette intelligentzia avec la culture allemande pendant les premières décennies du règne d'Isabelle II. Ces contacts ne produiront pas seulement un intérêt indéniable pour la culture allemande mais aussi tangentiellement pour la langue qui la véhicule. Le cas le plus voyant de cette nouvelle situation on le trouve à Madrid en 1840 avec la création de l'Academia Alemana-Española, fondée par un groupe où participent des Espagnols intéressés à la culture allemande - parmi eux quelquesuns d'origine allemande comme l'écrivain Juan Eugenio de Hartzenbusch et des krausistes - et des Allemands comme Julio Kühn qui sera auteur de la première grammaire de la langue allemande publiée en Espagne (Gramática alemana precedida de un cuadro histórico del origen y progresos de esta lengua ${ }^{2}$ [Grammaire allemande précédée d'un tableau historique de l'origine et des progrès de cette langue] (Madrid 1844) et le premier responsable d'une chaire d'allemand dans le lycée San Isidro de Madrid. Mais c'est à partir de 1860, puis à partir surtout de la décennie 1880 quand l'allemand, appuyé sur des causes politiques et socioculturelles que nous avons évoquées plus haut et dont nous reparlerons, parvient à trouver sa place en Espagne.

\section{L'influence allemande en Espagne à partir de $\mathbf{1 8 8 0}$ et l'enseignement de l'allemand}

3 La nouvelle situation concernant la culture et la langue allemandes commence surtout à donner ses fruits à partir, comme on a déjà dit, de la restauration de la monarchie en 1875. Au-delà de l'intérêt pour la philosophie krausiste, dont l'Institución Libre de Enseñanza représente son expression la plus accomplie, on assiste alors au prestige renouvelé de la culture allemande, qui s'appuie aussi sur la force incontestable de l'économie et de la technique de l'Empire allemand. C'est ce que signale alors dans son discours de réception à la Real Academia Española l'un des membres les plus actifs de l'Academia Alemana-Española, l'ingénieur des mines Agustín Pascual (1818-1884) qui avait fait des études spécialisées en Allemagne (à l'École de Tharandt, près de Dresde) :

$\mathrm{Ni}$ un momento he vacilado en la elección del tema para mi discurso. Ingeniero de montes, una ciencia vernácula de Alemania, tuve que comparar la lengua de los 
Fueros y las Partidas con la letra y el espíritu de los Códigos forestales, a fin de facilitar el camino de la enseñanza a la brillante juventud ${ }^{1}$ (Cité par Cáceres Würsig \& Marizzi $2010: 432$ ).

À partir de cette introduction où il souligne ses connaissances techniques d'ingénieur acquises en Allemagne, Pascual fait une approche linguistique très érudite sur les origines et l'évolution des langues espagnole et allemande, tout en essayant de suivre les apports de la philologie comparatiste de son temps. Mais ce qui nous intéresse plutôt c'est de mettre en évidence la critique qu'il fait à l'égard du système éducatif espagnol, aussi bien dans le secondaire qu'à l'université, à cause surtout de sa politique concernant les langues étrangères. Toutefois il ne met pas en question l'enseignement du français, qu'il juge nécessaire en tant que langue romane voisine. À son avis cette langue sert à découvrir une grande culture mais aussi à mettre en rapport la culture espagnole avec les autres grandes cultures européennes. Mais il prône pour autant l'apprentissage de l'allemand dans les universités espagnoles. Il compare leur situation avec celle des universités allemandes où l'intérêt pour les langues ne fait qu'augmenter au fur et à mesure que le siècle avance. Il attribue la méfiance des Espagnols à l'égard des langues des autres à l'histoire même de l'Espagne à partir du XVI ${ }^{\mathrm{e}}$ siècle et de la forte influence exercée par la Contre-réforme tridentine. Une réalité qui, d'après Pascual, est due spécifiquement, dans le cas des relations hispano-allemandes, au fait que « l'Espagne catholique a toujours jeté un regard méfiant vers tout ce qui provenait du pays de la Réforme » (cité par Cáceres Würsig \& Marizzi 2010 : 432).

Pascual, au-delà de son intérêt pour la culture et la science allemandes, pose clairement le problème de l'enseignement des langues vivantes dans l'Espagne de son temps. Surtout parce qu'il semble connaître bien les progrès qui se produisent alors dans les universités germaniques, dans le cadre des études philologiques et plus précisément de l'enseignement des langues. Mais si l'allemand continue à être dans les années 1870 une langue peu étudiée malgré les conseils d'Agustín Pascual, la présence de la culture et de la science allemandes en Espagne devient de plus en plus constante au détriment souvent de l'influence française, sans mettre pour autant en question la place hégémonique de la France. Mais les événements politiques de l'époque vont jouer au profit de nouvelles influences étrangères en Espagne.

6 C'est donc dans cette atmosphère favorable à la culture et à la science allemandes que Carlos Fernández de Castroverde $^{2}$, premier professeur d'allemand dans le lycée provincial de Barcelone, rédige sa grammaire, la première qu'on publie en Espagne après la « vieille grammaire » de Julio Kühn. Dans le prologue de ce manuel ${ }^{3}$ imprimé à Leipzig entre 1867 et 1868 , et qui connut deux rééditions (en 1887 et en 1891) à Barcelone, Fernández de Castroverde expose son point de vue sur la vraie situation de l'enseignement des langues étrangères en Espagne et pose la question en même temps, avec des arguments très favorables à l'allemand, à propos de l'intérêt et même de la nécessité d'apprendre cette langue. Dans un prologue, spécialement pertinent malgré un certain parti pris, il explique les raisons qui rendent indispensable, à son avis, l'enseignement de l'allemand aux Espagnols si ceux-ci veulent occuper la place qui leur appartient parmi les grandes nations européennes. Il tient compte de la nouvelle situation européenne où deux nouveaux pays (l'Angleterre et l'Allemagne) ont pris les devants de la scène au détriment de la France. L'Espagne devait donc réagir et chercher sa place à elle, prendre contact direct avec la culture et la science allemandes sans passer toujours par le filtre du français - et, dans une proportion moindre, de l'anglais -, ce qui ne ferait que les déformer : 
En España, más que en ningún otro punto de Europa, se hace cada día de mayor necesidad el estudio de una lengua, cuyas producciones literarias, tanto para las letras como para las ciencias exactas y naturales, entran en nuestras universidades e instituciones de enseñanza pública, deformadas, estropeadas y casi desconocidas por las retraducciones que sufren del francés o del inglés. Parece imposible que en este siglo llama-do de las luces ${ }^{4}$, aún no veamos en España germinar la inclinación, el deseo y el gusto de conocer a aquellos habitantes del Centro de Europa, que han dado al linaje humano los dos principales móviles de la civilización, como la pólvora y la imprenta ; aquellos hombres de profundo pensar y sano racio-cinio, a cuyas elevadas imaginaciones debemos aquello que se llama progreso material, social e intelectual ${ }^{5}$. (Fernández de Castroverde, 1867, t. 2 : VII-VIII)

Mais Fernández de Castroverde ne se limite pas à souligner l'importance de la culture et la science allemandes et leur grand apport au "progrès social et intellectuel », il reprend le « discours antifrançais » que beaucoup de ses contemporains faisaient pour mettre en question l'hégémonie culturelle française, devenue d'après eux de plus en plus « étouffante ». Ses mots dans ce long prologue de la première édition de 1867-1868 qu'il reprendra en partie dans celles de 1887 ( $2^{e}$ édition) et 1891 ( $3^{e}$ édition) montrent clairement la position de Fernández de Castroverde, spécialement critique envers les positions de ses compatriotes qu'il juge trop soumises à la culture et la langue françaises. Ce qui ne servirait pas, à son avis, à consolider une culture espagnole indépendante et bien ancrée dans la réalité contemporaine, mais plutôt à perpétuer un modèle culturel d'influence française qui se limite souvent à imiter et reproduire les grands apports de la culture et la science allemandes :

Verdad por cierto, bien triste es el decirlo, no deja de haber en España, entre los lectores de ambos sexos quien conozca y pueda dar razón de la literatura novelesca francesa de un ; Paul de Kock ! de un [sic] ; George Sand ! ... pero con raras excepciones, quien conozca a un Schiller para lo moral, lo ideal y lo bello; a un Leibniz y a un Liebig para lo sublime y científico. El estudio de la lengua francesa, que casi se hace obligatoria en España para toda carrera facultativa, solo sirve con escasas excepciones, para que el alumno conozca las reproducciones francesas, o sean las traducciones alemanas ${ }^{6}$. (Fernández de Castroverde 1867, t. 2 : XVIII)

En tout cas ce que prouve la position de Fernández de Castroverde, qui n'est pas d'ailleurs la seule, c'est que dans ces décennies finales du XIX ${ }^{e}$ siècle la relation des Espagnols avec les langues étrangères commence à changer. Pour cela il faudra tenir compte d'un concours de circonstances politiques et sociolinguistiques où les nouveaux rôles joués par les grands pays européens y sont pour quelque chose. Ce n'est pas par hasard si, à partir des années 1890 , on ouvre des écoles où on enseigne sous le mode allemand dans quelques grandes villes espagnoles : en 1894 à Barcelone, en 1896 à Madrid, puis en 1898 à Málaga. Ce qui coïncide d'ailleurs avec la publication d'un bon nombre de grammaires et de manuels pour l'apprentissage de l'allemand. À part la grammaire de Carlos Fernández de Castroverde, qui a connu plusieurs rééditions ${ }^{7}$, il faut citer, entre autres, le manuel de Luis de Belloc, Formación de las palabras en alemán: compendio indispensable y auxiliar de toda gramática alemana [Formation des mots en allemand: précis indispensable et auxiliaire de toute grammaire allemande] (Madrid, 1892) ; celui de Donato King, Clave de los temas de la gramática alemana [Clé des thèmes de la grammaire allemande] (Valence, $1898 ; 2^{\mathrm{e}}$ éd. 1900). Puis aussi, ceux de Juan San Emeterio de la Fuente, Gramática elemental de la lengua alemana (Madrid, 1900); et Eduardo Benot, Clave de los temas de la nueva Gramática Alemana para uso de los españoles (Madrid, 1900). Mais à part ces grammaires allemandes pas tout à fait novatrices, en tout cas moins qu'elles ne le prétendent, il faut citer la publication à Madrid en $1902 \mathrm{du}$ 
manuel d'allemand d'E. Ruppert, suivant la méthode Gaspey-Sauer. Il s'agit, sans doute, de l'un des livres pour l'apprentissage de l'allemand le plus utilisé en Espagne dans ces premières années $\mathrm{du} \mathrm{XX}^{\mathrm{e}}$ siècle. Tous ces exemples qu'on vient d'exposer sont spécialement significatifs, mais on pourrait en trouver encore d'autres comme c'est le cas de l'Institución Libre de Enseñanza (Institution Libre d'Enseignement), où l'influence de la " culture allemande », à travers diverses formes, sera présente du moment même de sa fondation en 1876 ; sans compter qu'en 1911 est créée à Madrid l'Escuela Oficial de Idiomas [École Officielle des Langues Étrangères] où l'allemand aura une place d'exception à côté du français et de l'anglais.

\section{L'enseignement des langues étrangères : le rôle de l'Institución Libre de Enseñanza}

9 L'Institución Libre de Enseñanza [ILE, à partir de maintenant] fondée en 1876, représente un pas décisif dans l'histoire de l'enseignement des langues étrangères en Espagne. Cette institution avait été fondée par des professeurs expulsés de l'Université de Madrid, la plupart appartenant au mouvement krausiste, parmi lesquels il faut signaler surtout Francisco Giner de los Ríos (Capitán Díaz 2002 : 293-298). Le souci principal de cette institution sera surtout de fonder l'éducation sur de nouvelles bases pédagogiques en marge de l'enseignement officiel, très influencé, dans ces premières années de la restauration monarchique, par la pensée conservatrice. Celle-ci, fortement imprégnée de la présence de l'Église catholique dans le système éducatif espagnol, essaiera d'imposer ses idées pédagogiques dans les différents plans d'études qui commenceront à voir le jour avec l'avènement d'Alphonse XII, après le sextennat révolutionnaire (1868-1874) et l'expérience éphémère de la Première République (1873-1874). Dans cet essai de rénovation pédagogique prôné par l'ILE il faut signaler un intérêt renouvelé pour l'enseignement des langues étrangères (Pérez-Villanueva 2011 : 738-741). On verra de la sorte, à partir des premières années de l'existence de cette institution, des professeurs de français, puis d'allemand et d'anglais faire partie de son personnel enseignant $^{1}$. Il s'agit de professeurs qui s'intéressent surtout aux nouvelles idées didactiques et pédagogiques concernant l'enseignement des langues. Indépendamment de la langue enseignée (le français principalement, mais aussi l'anglais et l'allemand voire l'italien), ces enseignants de l'ILE vont se tourner du côté de la méthode directe. Ils vont être en fait les principaux introducteurs de cette méthode qui coïncide pleinement avec leurs desseins pédagogiques novateurs dans toutes les disciplines scolaires. Ce qui deviendra possible grâce aux contacts que l'institution madrilène commence à nouer avec d'autres institutions scolaires et universitaires étrangères, notamment françaises, anglaises et allemandes, et cela dès le moment même de sa fondation. Ce qui expliquerait d'ailleurs, aux yeux des membres de l'ILE, l'intérêt pour les langues respectives de ces trois pays, dépassant ainsi l'influence monocorde de la culture française. C'est pour dire l'importance accordée à ces trois pays qu'on essaie d'imiter sans les suivre pour autant aveuglement, car il s'agirait finalement, d'après ce que préconisait l'ILE de régénérer la culture espagnole adoptant ce qu'il y a de mieux chez les autres mais sans aucune renonciation à ce qui lui était propre.

Quant à l'influence de la réforme axée sur la méthode directe, qui se fera sentir à partir de 1880 , il ne faudrait pas être dupe d'une fausse illusion. S'il est vrai qu'elle est très bien accueillie dans le cadre de l'ILE, il faudrait se poser la question à propos de 
l'utilisation qu'on en a faite. Tout compte fait, un bon nombre d'auteurs de manuels pour l'enseignement de langues étrangères - dont la plupart continuent à être, il faut le répéter, des manuels de français - souligneront l'importance de la méthode directe qu'ils prendront pour alibi afin d'attirer l'attention de leurs possibles usagers, même si eux-mêmes ne la suivent pas toujours. C'est ainsi qu'ils essaieront, avec plus ou moins de succès, d'avoir recours à cette méthode dans les années 1880 et 1890, puis dans les premières décennies du $\mathrm{XX}^{\mathrm{e}}$ siècle. Mais si on regarde de près les grammaires et les manuels de français, publiés dans les deux dernières décennies du XIX ${ }^{\mathrm{e}}$ siècle (Fischer, García Bascuñana \& Gómez 2004 : 251-260), et ceux d'allemand qui commencent alors à se publier, on ne découvre pas de grandes différences entre les uns et les autres. Exception faite du choix des textes dans certains de ces manuels, où on découvre, en principe, dans les manuels d'allemand une certaine attirance pour des textes plus diversifiés, avec une moindre présence du fait littéraire et une certaine attirance pour les textes scientifiques (Fernández de Castroverde 1887 : 501-735) ; contrairement à ce qui était courant dans les manuels de français depuis le temps de Francisco de Tramarría ${ }^{2}$. D'autre part, presque tous les nouveaux manuels d'allemand, qui commencent à se publier dans les deux dernières décennies du XIX ${ }^{e}$ siècle et les premières années $d u X X^{e}$, sont surtout des grammaires, où il ne manque pas d'explications pratiques afin de faire compréhensible aux Espagnols les points les plus complexes de la langue allemande. Mais les nouvelles méthodes ne sont pas toujours acceptées d'emblée et on trouve pas mal de résistance même de la part de ceux qui en principe nous apparaissent comme spécialement novateurs. C'est le cas de Fernández de Castroverde qui après avoir prôné l'innovation que représentait l'enseignement de l'allemand se montre plutôt conservateur quant à la méthodologie. Il refuse les "méthodes excessivement pratiques ", tout en laissant de côté aussi la méthode la plus traditionnelle fondée exclusivement sur la grammaire et la traduction. Il préfère une méthode plutôt éclectique :

Nuestro método se basa pues en las dos ideas fundamentales que deben siempre constituir no sólo el estudio de una lengua sino el de toda ciencia, cualquiera que esta sea, a saber: la teoría y la práctica ; la una es inseparable de la otra, y ninguna debe prevalecer sobre la otra [...]. No es posible adquirir dominio completo de una lengua por medio de un método puramente práctico, como han evidenciado hasta la saciedad los sistemas ollendorfianos, hoy ya relegados a la historia y al olvido ${ }^{3}$. (Fernández de Castroverde 1887 : VII)

\section{La culture et la langue allemandes au début du XX siècle}

11 Une question nous semble primordiale au sujet des langues autres que le français après cette nouvelle perception à l'égard des langues étrangères. Cela concerne leur enseignement dans le cadre scolaire officiel espagnol. La plupart des manuels (y compris ceux de français) qui paraissent alors en Espagne seront farcis de longs titres et commentaires qui soulignent les nouvelles influences linguistiques et philologiques dont une bonne partie provient surtout d'Allemagne voire d'Angleterre et des ÉtatsUnis. Tout cela va s'accompagner alors en Espagne d'une vraie germanophilie qui prend de nouvelles formes à travers un intérêt croissant pour la philosophie, la littérature et la musique allemandes (Ortiz-de-Urbina 2005 : 229-234). Dans le cas précis de la Catalogne, cette germanophilie prend une forme concrète qui venait déjà des dernières 
décennies du XIXe siècle : la passion pour les opéras de Wagner. Cet engouement pour la musique wagnérienne avait commencé très tôt, vers 1860, date où Josep Anselm Clavé fait la première audition à Barcelone de l'ouverture de Tannhäuser ; puis en 1874 on fonde la Société musicale Richard Wagner (dont il devient le président honoraire) et la revue La España musical. Sans compter les traductions en espagnol ou en catalan, d'œuvres littéraires et philosophiques allemandes qui se multiplient dans les premières années du nouveau siècle; puis aussi le rôle joué par certaine presse madrilène dans cette diffusion de la culture et la langue allemandes (Ortiz-de-Urbina $2004: 209-214$ ). Et on ne peut pas oublier non plus la présence de préceptrices germanophones au sein des grandes familles de la bourgeoisie madrilène jusqu'alors fortement "francisées". L'écrivaine et journaliste allemande Franziska Augstein nous donne à ce sujet, dans sa biographie de Jorge Semprún (Von Treue und Verrat. Jorge Semprún und sein Jahrhundert, Munich, 20081), un exemple concernant l'enseignement des langues étrangères, vers 1930-1936, au sein de la famille de cet écrivain espagnol d'expression française, une famille appartenant à la haute bourgeoisie éclairée madrilène :

La educación de los niños Semprún fue severa, aún más autoritaria de lo habitual entre la burguesía patriarcal española de principios del siglo XX. Las dos niñas y los cinco varones no acudían a escuela alguna. En su juventud Susana Maura [la madre de Jorge Semprún], educada en un colegio de monjas había querido ser maestra. Cuando sus hijos eran pequeños, les daba clase ella misma. De la enseñanza del alemán y del inglés se encargaban institutrices, que regulaban asimismo las actividades cotidianas. Más tarde tuvieron profesores particulares. En casa, los niños no podían hablar español entre ellos. Las hermanas tenían que entenderse en inglés, los chicos en alemán. El alemán era visto como un idioma importante y de especial dificultad ${ }^{2}$. (Augstein $2010: 34-35$ )

Et Augstein continue d'exposer les raisons alléguées par le père de Jorge Semprún pour justifier l'imposition de l'apprentissage de l'allemand à ses enfants, ou plutôt aux garçons de la famille, réservant aux filles l'apprentissage de l'anglais. Ce qui nous renseigne bien sur la position d'un bon nombre de familles de la bourgeoisie espagnole par rapport à l'allemand. Les arguments concernant «son importance culturelle et scientifique" et "sa capacité pour développer la rigueur intellectuelle " vont se répéter sans cesse lorsqu'on veut justifier son choix comme langue étrangère ${ }^{3}$.

El padre consideraba fundamental que los hijos aprendieran alemán, y con él la capacidad de pensar filosóficamente. Los españoles cultos de aquella época admiraban la cultura alemana. De niño, dice Semprún, soñaba en alemán. Sin embargo, el pensamiento filosófico pronto se fue a pique en el caos políglota. Como las niñas y los niños no podían entenderse entre ellos, vociferaban cada vez más alto en las lenguas que les habían asignado ${ }^{4}$. (Augstein 2010 : 35)

En tout cas, ce qu'il convient de souligner ici, au-delà de cette anecdote propre à la famille Semprún, c'est la place indiscutable qu'occupe alors l'allemand, malgré le paradoxe que cette situation provoque. Car on peut se demander quelle était en réalité la place du français dans le sein d'une famille éclairée de tradition républicaine comme était celle des Semprún ${ }^{5}$. Curieusement la langue étrangère que les membres de cette famille maîtrisaient le mieux était probablement le français. Peut-être pour cette raison, puisque le français était considéré à l'époque une langue étrangère passepartout, que toutes les familles éclairées de la haute bourgeoisie espagnole connaissaient plus ou moins bien, le père de Jorge Semprún fit ce choix clair pour l'anglais et surtout pour l'allemand. 


\section{En guise de conclusion}

De toute façon, le rôle des langues étrangères en Espagne, une fois qu'à partir de la seconde moitié du XIXe siècle la primauté du français " comme seule langue étrangère " commence à être mise en question, dépend très souvent de situations spécialement contradictoires. Presque aux mêmes années où Fernández de Castroverde, parmi d'autres, prônait la nécessité d'apprendre l'allemand et encourageait les Espagnols à abandonner définitivement le français et la culture française dans leurs rapports avec l'Europe, Nemesio Fernández Cuesta, traducteur, lexicographe et homme politique espagnol chantait encore en 1885-1886 (!) les excellences du français et donnait les raisons qui devaient pousser les Espagnols à le connaître car « il aspire à être la langue universelle et diplomatique par excellence » (Fernández Cuesta 1885-1886 : prologue, p. III). C'est pour dire les hésitations permanentes concernant la façon d'aborder en Espagne l'étude des langues étrangères. Peut-être leur éloignement des programmes universitaires et leur statut particulier, si on les compare avec ce qu'on considérait les " matières nobles ", y étaient pour quelque chose. Les langues étrangères devaient donc chercher leur propre chemin, "s'opposant " parfois entre elles mais en même temps étant obligées de faire cause commune pour trouver leur place dans le cadre scolaire institutionnel, où le français continuera d'être dans la pratique, à quelques exceptions près, et malgré les nombreux va-et-vient, la principale langue étrangère enseignée, comme on a déjà plusieurs fois souligné au long de cette étude. Et cela jusqu'aux années 1970 où l'anglais viendra prendre la relève. Mais certaines situations politiques pourraient jouer aussi dans ces hésitations et contradictions. Car s'il est vrai, comme on a dit plus haut (Ortiz-de-Urbina 2004 et 2005), qu'une bonne partie de la presse espagnole, spécialement la madrilène, faisait étalage d'une vraie germanophilie entre 1900 et 1914, il n'est pas moins vrai que l'éclatement de la Première Guerre mondiale va tout changer décidemment. Car même si l'Espagne ne participe pas directement à cette guerre, cela n'empêche que les Espagnols prennent parti pour l'un ou l'autre des pays en guerre : les empires centraux, et tout spécialement l'Allemagne étaient vus comme les pays qui représentaient la discipline, l'autorité, l'ordre et l'efficacité, tandis que les alliés (la France et l'Angleterre) étaient vus comme les représentants du libéralisme et la démocratie. De sorte que les syndicats et partis de gauche préféraient s'identifier avec ceux-ci, tandis que l'aristocratie, les secteurs les plus conservateurs et l'armée s'alignaient plutôt sur les premiers. On devenait ainsi germanophile ou alliophile, ou bien tout simplement francophile ou anglophile avec les répercussions que cela comportait. Si bien qu'apprendre le français, l'anglais ou l'allemand devint en Espagne, entre 1914 et 1918, une décision essentiellement politique. Mais une fois la guerre finie, d'autres facteurs prirent le dessus et on revint pour un temps à la situation antérieure à la guerre, au moins jusqu'en 1930, point culminant d'une longue période de plusieurs décennies qui a marqué décisivement l'histoire de l'enseignement des langues étrangères en Espagne. 


\section{BIBLIOGRAPHIE}

AUGSTEIN, Franziska (12010). Jorge Semprún. Lealtad y traición. Barcelona : Tusquets editores [1 $1^{\mathrm{e}}$ éd. allemande München : Beck, 2008].

CÁCERES WÜRSIG, Ingrid \& MARIZZI, Bernd (2010). « La Academia alemana-española de Julio Kühn : relato de un proyecto de colaboración científica y cultural ». Estudios Filológicos Alemanes, $20,415-436$.

CAPITÁN DÍAZ, Alfonso (2002). Breve historia de la educación en España. Madrid : Alianza Editorial.

FERNÁNDEZ DE CASTROVERDE, Carlos (1867-1868). Nuevo método teórico y práctico escrito especialmente para los españoles y aquellos que poseen la lengua castellana (2 t.). Leipzig: Brockhaus ( $2^{\mathrm{e}}$ éd. Barcelona : Tip. La Academia, 1887; $3^{\mathrm{e}}$ éd. Barcelona : Tip. La Academia, 1891).

FERNÁNDEZ CUESTA, Nemesio (1885-1886). Dictionnaire français-espagnol, espagnol-français (4 t.). Barcelona : Montaner y Simón.

FISCHER, Denise, GARCÍA BASCUÑANA, Juan F. \& GÓMEZ, Maria Trinidad (2004). Repertorio de gramáticas y manuales para la enseñanza del francés en España (1565-1940). Barcelona : PPU.

KÜHN, Julio ( $\left.{ }^{2} 1852\left[{ }^{1} 1844\right]\right)$. Gramática alemana : precedida de un cuadro histórico del origen y progreso de esta lengua. Madrid : Imprenta Nacional.

ORTIZ-DE-URBINA Y SOBRINO, Paloma (2004). « El papel de la prensa diaria madrileña en la difusión de la lengua y cultura germánicas : 1900-1914». In M. Beltrán (éd.). Estudios interdisciplinares sobre lenguas modernas. Una perspectiva intercultural. Madrid : Servicio de Publicaciones Fundación Universitaria San Pablo, 207-223.

ORTIZ-DE-URBINA Y SOBRINO, Paloma (2005). «El interés por la cultura germánica en España durante los primeros quince años del siglo XX : orígenes y consecuencias ». Estudios Filológicos Alemanes, 9, 229-240.

PÉREZ VILLANUEVA TOVAR, Isabel (2011). La residencia de estudiantes 1910-1936. Grupo universitario y residencia de señoritas. Madrid: Publicaciones de la Residencia de Estudiantes CSIC AC/E.

\section{NOTES}

1. Les différents exils qui s'en suivent en Europe après les guerres napoléoniennes, puis pour le cas concret de l'Espagne après les deux retours de Ferdinand VII (1814, après la victoire contre les troupes françaises, et 1823 après la défaite des libéraux du triennat révolutionnaire de 1820-1823) serviront à établir ces nouvelles relations.

2. Cette grammaire est en réalité une adaptation de la Theoretisch-praktische deutsche Grammatik de Johann Christian August Heyse (1764-1829) qui avait été publiée en 1827.

1. Je n'ai pas douté au moment de choisir le sujet pour mon discours. En tant qu'ingénieur des eaux et forêts, une science née en Allemagne, je fus contraint de comparer la langue des Coutumes et les recueils de lois avec la lettre et l'esprit des Codes forestiers, afin de frayer le chemin de l'enseignement à une jeunesse resplendissante [trad. APD].

2. Grâce à la page de titre, on apprend que Carlos Fernández Castroverde était docteur en philologie de l'Université de Berlin et qu'avant de s'installer à Barcelone il avait enseigné des langues (on ne dit pas lesquelles) aux États-Unis, plus exactement à Philadelphie et à la NouvelleOrléans. 
3. Le titre complet est: Gramática alemana. Nuevo método teórico y práctico para los españoles y aquellos que posean la lengua castellana [Grammaire allemande: Nouvelle méthode théorique et pratique pour les Espagnols et tous ceux qui maîtrisent la langue castillane].

4. Fernández de Castroverde emploie curieusement l'expression "siècle des lumières ", qu'on applique normalement au XVIII ${ }^{\mathrm{e}}$ siècle, pour se référer au XIX ${ }^{\mathrm{e}}$.

5. En Espagne, plus que dans n'importe quel autre endroit d'Europe, l'étude de cette langue [l'allemand] devient de plus en plus nécessaire, car ses productions écrites (aussi bien pour les lettres que pour les sciences exactes et naturelles) entrent déformées, abîmées et difficiles à reconnaitre dans nos universités et institutions d'enseignement public à cause des retraductions qu'elles subissent à travers le français et l'anglais. Il semble impossible que dans notre siècle des lumières, nous ne voyons pas encore en Espagne germer l'inclination, le désir et l'envie de connaître les habitants de l'Europe centrale, qui ont donné au genre humain les deux principaux instruments de la civilisation : la poudre et l'imprimerie; ces hommes, maîtres d'une pensée profonde et d'un raisonnement sain, à qui, grâce à leurs imaginations élevées, nous devons ce qu'on appelle progrès matériel, social et intellectuel [trad. APD].

6. Il est vrai, il faut l'admettre qu'il est difficile de trouver en Espagne, parmi les lecteurs des deux sexes, quelqu'un qui ne connaisse pas et ne sache pas expliquer la littérature romanesque d'un Paul de Kock! d'un [sic] George Sand! ... mais il est par contre presque impossible de trouver quelqu'un qui connaisse un Schiller pour la moralité, l'idéal et la beauté ; un Leibniz et un Liebieg pour le sublime et l'esprit scientifique. L'étude de la langue française, qui devient presque obligatoire en Espagne pour les études scientifiques, sert seulement, à quelques exceptions près, pour que l'élève connaisse les reproductions françaises, c'est-à-dire les traductions de l'allemand [trad. APD].

7. Au moment de la seconde édition de 1887, Fernández de Castroverde à élargi le titre de sa grammaire. À cette deuxième édition de 1887 que pour des raisons pratiques il réduit à un seul volume (la première édition, comme on a dit, en comptait deux), il donne le titre suivant: Gramática alemana. Nuevo método teórico práctico con crestomatía y clave de los temas al uso especial de los españoles y de los que posseen la lengua castellana [Grammaire allemande. Nouvelle méthode théorique et pratique, avec une chrestomathie et la clé des thèmes à l'usage des Espagnols et de ceux qui maîtrisent la langue castillane]. Ce même titre de la deuxième édition se répète dans la troisième (1891).

1. Être professeur dans l'ILE devient un signe de modernité qu'on met bien en évidence. C'est ce que font beaucoup de professeurs de l'époque pour renforcer leur statut professionnel. Enrique Benavente, auteur d'un manuel de français paru en 1888, El idioma francés puesto al alcance de los españoles...[La langue française mise à la portée des Espagnols], signale qu'il « a été professeur de français à l'Institución Libre de Enseñanza » (Fischer, García Bascuñana \& Gómez 2004 : 98).

2. Le premier choix de textes de Tramarría, Leçons françaises de littérature et de morale (Cadix, 1839) avait été publié pour servir de complément à sa Gramática francesa para uso de los españoles [Grammaire française à l'usage des Espagnols] publiée à Madrid en 1829.

3. Notre méthode est fondée donc sur les deux idées fondamentales qui doivent toujours constituer non seulement l'étude d'une langue mais celui de toute science, n'importe laquelle, c'est-à-dire : la théorie et la pratique; l'une est inséparable de l'autre, et aucune idée ne doit s'imposer contre autre [...]. Il n'est pas possible d'acquérir une maitrise complète d'une langue à travers une méthode purement pratique, comme l'ont montré clairement les systèmes ollendorfiens, aujourd'hui relégués dans les oubliettes du temps et de l'histoire [trad. APD].

1. [Loyauté et trahison. Jorge Semprún et son siècle]. Nous avons utilisé pour notre étude la traduction espagnole, publiée en 2010 (voir bibliographie).

2. L'éducation des enfants Semprún fut sévère, encore plus autoritaire de ce qui était habituel au sein de la bourgeoisie patriarcale espagnole du début du $\mathrm{XX}^{\mathrm{e}}$ siècle. Les deux filles et les cinq garçons n'allaient à aucune école. Dans sa jeunesse Susana Maura [la mère de Jorge Semprún], 
élevée dans un collège tenu par des sœurs, avait voulu être institutrice. Lorsque ses enfants étaient petits, c'était elle-même qui leur faisait des cours. De l'enseignement de l'allemand et de l'anglais se chargeaient des préceptrices, qui organisaient aussi les activités quotidiennes. Plus tard ils eurent des professeurs particuliers. À la maison, les enfants ne pouvaient pas parler en espagnol entre eux. Les filles devaient se faire comprendre en anglais, les garçons en allemand. L'allemand était vu comme une langue étrangère importante et spécialement difficile [trad. d'APD].

3. La famille Semprún avait engagé une préceptrice germanophone, provenant de la Suisse alémanique, pour enseigner l'allemand aux garçons de la maison.

4. Le père considérait nécessaire que les fils apprissent l'allemand, ce qui devait procurer la capacité de penser philosophiquement. Les Espagnols cultivés de l'époque admiraient la culture allemande. Quand il était enfant, nous dit Semprun, il rêvait en allemand. De toute façon la pensée philosophique fit bientôt naufrage dans ce chaos polyglotte [trad. d'APD].

5. Le père José María Semprún Gurrea, professeur de Philosophie du Droit à l'Université de Madrid appartenait à la gauche chrétienne, étant le représentant de la revue française Esprit en Espagne. Républicain convaincu, il embrassera très tôt cette cause, ce qui le portera à l'exil, après avoir été, entre 1937 et 1939, chargé d'affaires dans l'ambassade de la République espagnole à La Haye. Il était en plus très proche des idées de l'Institución Libre de Enseñanza.

\section{RÉSUMÉS}

C'est à partir des nouvelles relations culturelles hispano-allemandes entre 1880 et 1930 et la situation politique qui s'en est suivie, que l'Espagne s'intéresse à la culture allemande, puis à la langue qui la véhicule, même si le français continue à s'imposer pratiquement partout comme langue étrangère. Les manifestations sont diverses : une vraie germanophilie prend forme dans un intérêt croissant pour la philosophie, la philologie, la littérature et la musique allemandes (la passion pour les opéras de Wagner); l'ouverture des écoles allemandes à Barcelone (1894), Madrid (1896) et Málaga (1898); la publication d'un bon nombre de manuels d'allemand à l'usage des Espagnols; la présence de préceptrices germanophones au sein des familles de la bourgeoisie madrilène - jusqu'alors «francisées ». Nous abordons aussi le cas particulier de l'Institución Libre de Enseñanza où l'influence de la "grande culture allemande" se fait très présente. Sans répercussions pourtant sur le cadre scolaire institutionnel où le français continuera d'être dans la pratique la seule langue étrangère enseignée. Et cela jusqu'aux années 1970 où l'anglais viendra prendre la relève.

The new Hispano-German cultural relations between 1880 and 1930 and the political situation that emerged led to Spain taking an interest in German culture and language, despite the fact that French continued to dominate practically all fields as a foreign language. This newfound interest took on various forms: a real Germanophilia took hold through a growing interest in German philosophy, philology, literature and music (the passion for Wagnerian operas); German schools were opened in Barcelona (1894), Madrid (1896) and Málaga (1898); German tutors were hired by bourgeois Madrid families, who until that time had been lovers of all things French. Here we focus on the particular case of the Institución Libre de Enseñanza (Free Institute of Education), which was considerably influenced by the "grand German culture". However, none of this was to have any effect on the institutional school framework in which French was, 
practically speaking, still the only foreign language taught. And it was to remain so until the 1970s, when English was to take over.

INDEX

Mots-clés : enseignement des langues étrangères, manuels, français, allemand, Institución Libre de Enseñanza, culture, écoles allemandes

Keywords : foreign language teaching, textbooks, French, German, Institución Libre de Enseñanza, culture, German schools

\section{AUTEUR}

ALICIA PIQUER DESVAUX

Universitat Barcelona, Espagne

apiquer@ub.edu 